\title{
CORRIGENDUM
}

\section{Phenotypic and genetic variation in leptin as determinants of weight regain}

G Erez, A Tirosh, A Rudich, V Meiner, D Schwarzfuchs, N Sharon, S Shpitzen, M Blüher, M Stumvoll, J Thiery, GM Fiedler, Y Friedlander, E Leitersdorf and I Shai

International Journal of Obesity (2012) 36, 1372; doi:10.1038/ijo.2012.154

Correction to: International Journal of Obesity (2011) 35, 785-792; doi:10.1038/ijo.2010.217; published online 2 November 2010

Since the publication of this paper, the author has noticed that the author name E Leiterstdorf has been listed incorrectly. The correct spelling is $\mathrm{E}$ Leitersdorf. 